\title{
Pregnant surgeon - assessment of potential harm to the woman and her unborn child
}

\author{
Aleksandra Szczesna ${ }^{1}$, Kinga Grzelak ${ }^{1}$, Monika Bieniasz² , Joanna Kacperczyk-Bartnik ${ }^{3}$, \\ Agnieszka Dobrowolska-Redo ${ }^{3}$, Pawel Bartnik ${ }^{3}$, Julia Zareba-Szczudlik ${ }^{3}$, \\ Ewa Romejko-Wolniewicz ${ }^{3}$ \\ 'Students' Scientific Group affiliated to 2nd Chair and Department of Obstetrics and Gynecology, \\ Medical University of Warsaw, Warsaw, Poland \\ ${ }^{2}$ Department of Gastroenterological Oncology, Maria Skłodowska-Curie Memorial Cancer Centre \\ and Institute of Oncology in Warsaw, Warsaw, Poland \\ ${ }^{3} 2$ nd Chair and Department of Obstetrics and Gynecology, Medical University of Warsaw, Poland
}

\begin{abstract}
Although most countries developed regulations concerning pregnant women at work, they are not strictly adjusted for every profession. In the European countries directives prevent pregnant women from working during night shifts, but apart from a vague paragraph about avoiding hazardous agents, there are no guidelines specific for pregnant surgeons. The aim of the study was to analyse the risks and consequences of working in the operating theatre during pregnancy. An in-depth analysis of available literature, laws and regulations concerning health and safety of pregnant surgeons was performed. Not only they are surgeons exposed to radiation and infectious agents like any other physicians, but they also face the risk of strenuous physical activity affecting their pregnancy. The unpredictability of this occupation, prolonged hours and stress associated with work can all affect the future mother and her child. The available research on potential risks for pregnant women performing surgical activities named such consequences as premature birth, miscarriage, foetal growth retardation, hypertensive disorders and infertility. There are no unanimous guidelines for pregnant surgeons on how long and to which extent they should work. The key is to maintain a balance between limiting the likelihood of pregnancy complications and respecting women's voluntary wish to continue professional development.
\end{abstract}

Key words: fetal development; pregnancy; reproductive behaviour; surgeons; surgery

Ginekologia Polska 2019; 90, 7: 470-474

\section{INTRODUCTION}

In the light of a growing number of female doctors performing surgeries, there is a need to study the risks and consequences of working in the operating theatre during pregnancy. Although most countries have legal regulations concerning pregnant women at work, they are not strictly adjusted for every profession. In the European countries the directives prevent pregnant women from working during night shifts, but apart from a vague paragraph about avoiding hazardous agents, there are no guidelines specific for pregnant surgeons [1].

Not only are surgeons exposed to radiation and infectious agents like any other physicians, but they also face the risk of strenuous physical activity. The unpredictability of this occupation, prolonged hours and stress can all affect foetal development. Most of listed risk factors have been analysed in various studies in order to examine whether there is any association between performing surgeries and unfavourable pregnancy outcomes such as miscarriage, intrauterine growth restriction (IUGR) or preterm delivery. A questionnaire conducted in Germany did not reveal any increase in the risk of complications among pregnant surgeons in comparison to the general population [2]. Another study proved a correlation between preterm delivery and long working hours, shift work, lifting, standing and heavy physical workload, all of which are included in surgeon's activities [3].

Considering the increasing proportion of women in healthcare, there is a growing number of female doctors who work in operating theatres. Not only does this apply to surgeons, but also to gynaecologists, interventional radiologists and other specialties. There are medical fields in which 
significantly less female doctors decide to practice than male doctors, as observed distinctly among orthopaedic surgical trainees. This even led to discussion whether sex determined selection results in annual residency applications [4]. The issue was assessed by Baerlocher [5], who concluded no occurrence of such discrimination. He highlighted that the underlying reason for such sex distribution is explicitly connected with conscious choice of career path. "Work-life balance" stands as a main deterrent to pursuing surgery professional career among junior female doctors [6]. Female surgeons with children stated that "children and family" tended to hinder their careers [7]. For the fear of falling behind their male colleagues or extension of training and even exclusion from surgery, women postpone their decision of pregnancy. But notwithstanding those drawbacks, percentage of women enrolled in medical career path outnumbered men in some countries like the UK. According to the Universities and Colleges Admissions Service (UCAS) almost $60 \%$ of accepted applicants for medical studies were female [8]. Such sociologic transformation entails enforcement of law towards childbearing-friendly surgical training programs. Statistically, most of female surgeons have at least one child during their career and do not cease their surgical activities until $21^{\text {st }}$ gestational week [2]. It is not clearly restricted, at which stage of gestation women are advised to stop operating. Moreover, it is shown that there is a predilection among consultants to cease operating significantly later in comparison to assistant doctors [2]. Also, more experienced surgeons holding higher positions show a tendency to inform their supervisors about their pregnancy later than their younger colleagues [2]. In a Germany-wide survey $80 \%$ of female gynaecologists and surgeons expressed a desire for a change of the law that strains from work and/or traineeship [2]. Therefore, there is a strong need to study potential risk factors and consequences of performing surgeries for pregnant doctors.

\section{Laws and regulations}

In countries associated under the European Union flag, European Commission law is in force. Council Directive 92/85/EEC "Protecting pregnant workers and new mothers" with its amendments states the main restrictions in the field of pregnant female work [9]. The main regulations apply to risks posed by hazardous substances and industrial processes, working condition in still posture, exposure to biological, chemical or physical agents, and night shifts. Allowance of undergoing antenatal examinations during working hours, the constant position at work and reassurance that pregnancy cannot cause dismissal are also regulated in the above directive. The employer should not only inform the pregnant woman about the contact with hazardous substances or other risk factors, but also is entailed to assure the safety from damage to her health in workplace.
In Poland the law obliges the employer to shift the pregnant/breastfeeding women from hazardous work to workplace within safe conditions, pare down working hours, or even grant the woman health and safety leave for the time of pregnancy. However, such actions should not affect her salary [10]. All the restrictions are discussed in greater detail in the Journal of Laws of the European Union and they aim to reduce strain from labour or exposure to hazardous agents [11]. Although the law is precisely addressing the risk factors, it does not implement to healthcare professionals and to the subject of pregnant surgeons. Evaluation in this area is to be considered as it was expressed explicitly in the survey among female surgeons and gynaecologists [2].

An attempt to implement the law protecting pregnant doctors was embodied in Heidelberger Schwangerschafts \& Elternzeitprogramm (HeiSEP) [12]. This program fosters the decision of childbearing among young doctors, giving them a chance to plan their future career via precise and long-range plan, which consists of sections as follows: integration in the clinic, continuation of academic development, status of trainee program, continuation of professional development, and reintegration after the maternity leave. Due to such mutual exchange of possibilities and preferences between the pregnant and her employer it is possible to adjust activities in the clinic, ranging from operating to scientific work. Such flexibility does not exclude pregnant or breastfeeding women from attending surgeries and offers continuous development of practical skills.

\section{Risk factors}

Gravid or lactating women in the surgical ward are exposed to hazardous substances, which might affect pregnancy outcomes. These hazards may be divided into physical, biological, and chemical [13]. Biological hazards include mostly blood-borne pathogens. However, some infections, e.g. human papilloma virus, are known to be carried in the smoke plumes generated by laser and electrosurgical devices. Solid chemical hazards are found primarily in the form of chemical disinfectants. While liquid chemicals are used primarily in disinfection, sterilization, medication, and tissue preservation, gas chemicals are primarily associated with anaesthesia, disinfection, sterilization, and surgical equipment. Physical hazards can also occur, as a thermal hazard of an autoclave or high-pressure gases used in the operating theatre. A rapidly developing foetus is much more susceptible to low dose exposure to hazardous materials than an adult [14].

Pregnant women working in healthcare institutions are exposed to infectious diseases. Pregnancy, however, does not seem to be an independent risk factor for occupationally acquired infectious diseases, but it seems imperative to make use of primary prevention and obedience to infec- 
tion control precautions. Prevention extends from obligatory staff immunization to regular up-to-date vaccination against influenza and pertussis. Pregnant healthcare workers (HCWs) with occupational exposure to communicable diseases should be directed immediately for appropriate post-exposure prophylaxis and observed for development of active infection [15]. Annual mean rates of needle stick injuries and blood contact cases per 1,000 employees by different risk groups show that in surgery -12.0 needle stick injuries (NSIs) and 0.6 blood contact cases (BCCs) - there is a smaller risk of contracting a blood-borne disease than in hospital overall (29.9 NSIs and 2.8 BCCs per 1000) [16]. This implies that pregnant surgeons who want to continue their work in the operating theatre are not more exposed to viral infections than other HCWs. The most frequently mentioned risk associated with harm to foetal development is associated with biological agents, such as viral infections: HCV, HIV, Rubella Virus, CMV, Human Parvovirus B19, VZV as well as bacterial: L.monocytogenes, or parasitic infections: T. gondii $[17,18]$. Other biological agents qualified as detrimental to employees' health which cause harm to pregnant female or impair foetal development are Ebola virus, S. typhi or S. dysenteriae $[17,18]$.

When discussing a pregnant female conducting surgery, other risk factors of adverse pregnancy outcomes should be also mentioned. Among these are using puncturing instruments, surgery duration over 4 hours, night shifts and responsibility during emergencies [19]. In an nation-wide survey conducted among Hungarian women, reproductive health was compared between physicians and controls [20]. In this study the burn-out syndrome was classified as the firm predictor of stress characteristic for medical profession. Female doctors continue working while pregnant, which may affect the outcome of pregnancy, as work stress is an explicit risk factor for various complications [20, 21]. Female physicians were bearing more high-risk pregnancies ( $26.3 \%$ vs. $16.3 \%$ ) compared with the general female population [21]. Moreover, female physicians are documented to have longer time-to-pregnancy interval and more frequent infertility treatment during the reproductive age than the control group.

Waters and Dick compared studies evaluating the effect of long standing hours on pregnancy outcomes such as low birth weight (LBW), preterm birth, stillbirths, and late spontaneous abortions [22]. There is an explicit association between the strained still erect body position of duration over 8 hours per day, classified as prolonged standing and pathological pregnancy events. Although regular physical activity during pregnancy is in fact recommended by the American College of Obstetricians and Gynecologists (ACOG) with differentiation between safe sports such as low-impact aerobics, jogging or swimming and risky sports which can cause mechanical harm to foetus, such as contact sports [23]. Overall, the benefits of exercise exceed potential risks, with some exceptions, when women bear a complicated pregnancy. Nonetheless, extrapolation of such benefit according to occupational physical activity may present problems, as the border separating beneficial exercise from potentially hazardous level of activities is vague.

\section{Consequences}

Prolonged and exhausting line of work during pregnancy can result in premature birth. This was the complication which was detected most often in German studies among pregnant surgeons, with $7.1 \%$ of them reporting to have experienced premature birth and $2 \%$ perceiving this complication as a result of surgical activities [2]. Other complications mentioned in the survey included miscarriage (2.9\%), IUGR (2.9\%) and premature rupture of membranes (PROM) $(0.6 \%)$. However, none of these consequences correlated either with the number of hours spent during surgery, or with the time of stepping down from surgical obligations. The incidence of those complications was not higher than in the general population, in which the risk of IUGR is $8.9 \%$, of miscarriage $12-31 \%$, of premature birth $5-7 \%$, and of the occurrence of PROM 2.9-3.5\% [24-26]. Other complications including pelvic pain and vaginal bleeding were neither associated with the number of hours spent at work.

According to the systematic review by Bonzini et al. [3] physical challenges at work can result in an increased number of complications during pregnancy. Authors analysed the relationship between three adverse outcomes of pregnancy (preterm delivery, LBW and gestational hypertension) and five occupational exposures (long working hours, shift work, lifting, standing, and heavy physical workload). The main message was that preterm delivery was related to each of these exposures. Fewer links were found between other outcomes. At the surgical ward a pregnant doctor faces combination of prolonged standing position with heavy lifting and bending, which may lead to lowering the uterine blood flow and intra-abdominal pressure increase [27]. Although the evidence is not strong enough to support mandatory restrictions for professions with the risk of strenuous activities, there is a clear recommendation towards the limitations of demanding activities.

Also, timing of reproduction during the medical career has an impact on its outcome. Undertaking pregnancy during residency training increases the risk of adverse events [28]. Certain complications have a higher likelihood of occurrence among residents than specialists due to different character of their work [28]. Longer operating hours and more than six night shifts per month predispose residents to more obstetric complications. In addition, pregnant residents are more likely to develop hypertensive disorders, IUGR, placental 
abruption, and miscarriage than pregnant women of similar age in the general population [28].

As Zhang et al. [29] investigated in their study that occupational exposure to radiation, chemicals and noise is associated with increased risk of antepartum foetal death, birth defects, small-for-gestational-age, and spontaneous abortion. Moreover, working in healthcare or research sector shows concomitance with numerous reproduction pathologic outcomes such as fertility problems, late spontaneous abortions, prematurity, chromosomal anomalies, mental retardation, and childhood cancer events among offspring [29]. In 1997 Zadeh and Briggs attempted to evaluate the risk of $\mathrm{X}$-ray radiation on reproduction, weighting up two groups: surgeons and obstetricians. The conclusion, however, indicated that working in healthcare sector is the occupational hazard itself. Data obtained from questionnaires sent to orthopaedic surgeons, gynaecologists and obstetricians revealed a significantly higher prevalence of congenital anomalies in offspring than in the general population [30].

\section{Prevention}

The European Agency for Safety and Health at Work imposed on EU countries limits maximum value of occupational exposure to chemical, physical and biological agents. The European Framework Directive on Safety and Health at Work (Directive 89/391 EEC) adopted in 1989 serves as an obligation for employers to create a safe working conditions. This issue is regulated in the Directive 92/85/EEC with emphasis on pregnant and breastfeeding women [1]. The consequences of the mentioned law are reflected in prophylactic actions undertaken by employer such as measurement of exposure to risk factors, notifying the gravid or lactating staff about the jeopardy, evaluation of potentially hazardous activities, submission to safety procedures, regulations restricting night shifts and additional workload as well as adjustment of the workplace to childbearing personnel. When considering HCWs, the national healthcare organization is obliged to obey current guidelines minimizing occupational hazard of biological, physical, chemical agents, with special care for female staff in the reproductive age.

According to guidelines established in 1998 by Hospital Infection Control Practices Advisory Committee of Centers for Disease Control and Prevention (CDC) detailed strategies of preventing infectious diseases among HCWs are recommended [31]. Among those are vaccination, isolation precautions, management of exposure to infectious agents, work restrictions for exposed or infected worker. The health service for personnel is responsible for educating the employees about the principles of infection control, collaborating with infectious control department to observe the epidemiology of diseases, providing care for employees bearing work-related illnesses, identifying and measuring occupational risk, containing costs by preventing diseases resulting in absence or disabilities.

As the risk of occupational infectious diseases contracted at hospital is high, proper hand hygiene, vaccination and protective equipment like gloves or safety devices are important in minimizing the risk [17]. Specific recommendations according to doses and type of vaccines are to be found in the review by Lynch and Spivak [15]. Women in the childbearing age are encouraged to receive immunization for vaccine-preventable diseases. Adherence to precautions and safety procedures when taking care of infected patients is an imperative. According to the CDC Guidelines, there is no study stating whether transferring seronegative staff to areas with less contact with patients who are reservoir of CMV decreases the risk of infection during pregnancy, for CMV can survive on surfaces and objects for short period of time [31]. Additionally, HCWs who provide help to high-risk contagious patients present similar prevalence of primary CMV infection as the other workers without such contact [31]. Using standard precautions and proper hand hygiene is recommended as sufficient to reduce the risk of transmission.

Strain and following harm to pregnancy outcome associated with imposed body position during pregnancy when reaching the task on the table can be decreased with using a proper interventions. These are as follows: using compression stockings or support hosiery, flooring condition, floor mats, shoe inserts, sit-stand workstations and ergonomics pre-trainings [22].

Improvement of working conditions and prevention of burnout syndrome appear to be important factors in prevention of unfavourable pregnancy outcomes. Holistic approach involves work-process efficacy, well-balanced workload, cooperative hospital management and organization, colleagues' support, work-home balance, feeling of control, and personal situation such as parenthood [32]. As it was studied by Roberts et al. having children is crucial for mental and physical health of HCWs [33]. The parenthood seems to be essential as in one survey stated, burnout syndrome is rather a consequence than a cause of reproductive morbidity among female doctors. Organization of work during pregnancy allowing constant development of one's personal professional skills is of a special concern for care of mental health.

\section{CONCLUSIONS}

The need for risks assessments of harm to pregnant doctors working in surgery is increasing in the light of a growing number of female doctors. There are no unanimous guidelines for pregnant surgeons on how long and to which extent they should work. The key is to maintain balance between limiting the likelihood of pregnancy complications and respecting women's voluntary wish to continue profes- 
sional development. Most important risk factors include occupational stress, long and unpredictable working hours, exhausting line of work and exposure to infections. They can be related to consequences such as premature birth, miscarriage, foetal growth retardation, hypertensive disorders and infertility. Nonetheless, due to a small scale of various studies and limited number of enrolled subjects, further research is needed.

\section{REFERENCES}

1. European Agency for Safety and Health at Work. Directive 92/85/EEC pregnant workers. https://osha.europa.eu/pl/legislation/directives/10. (14th January 2019).

2. Knieper C, Ramsauer B, Hancke K, et al. "Pregnant and Operating": Evaluation of a Germany-wide Survey Among Female Gynaecologists and Surgeons. Geburtshilfe Frauenheilkd. 2014; 74(9): 875-880, doi: 10.1055/s-0034-1383065, indexed in Pubmed: 25278630.

3. Bonzini M, Coggon D, Palmer KT. Risk of prematurity, low birthweight and pre-eclampsia in relation to working hours and physical activities: a systematic review. Occup Environ Med. 2007; 64(4): 228-243, doi: 10.1136/oem.2006.026872, indexed in Pubmed: 17095552.

4. Pico K, Gioe TJ, Vanheest A, et al. Do men outperform women during orthopaedic residency training? Clin Orthop Relat Res. 2010; 468(7): 1804-1808, doi: 10.1007/s11999-010-1318-4, indexed in Pubmed: 20333491.

5. Baerlocher MO. Does sex affect residency application to surgery? Can J Surg. 2007; 50(6): 434-436.

6. Kerr HL, Armstrong LA, Cade JE. Barriers to becoming a female surgeon and the influence of female surgical role models. Postgrad Med J. 2016; 92(1092): 576-580, doi: 10.1136/postgradmedj-2015-133273, indexed in Pubmed: 27528701.

7. Mayer KL, Ho HS, Goodnight JE. Childbearing and child care in surgery. Arch Surg. 2001; 136(6): 649-655, doi: 10.1001/archsurg.136.6.649, indexed in Pubmed: 11387001.

8. Universities and Colleges Admissions Service. Applications and acceptances for types of higher education course - 2017. https://www. ucas.com/corporate/data-and-analysis/ucas-undergraduate-releases/ucas-undergraduate-end-cycle-data-resources/applications-and-acceptances-types-higher-education-course-2017 (14th January 2019).

9. Directive $92 / 85 / E E C$ - pregnant workers on the EU Agency for Safety and\& Health at work, 2015. http://eur-lex.europa.eu/legal-content/EN/TXT/?uri=legissum:c10914 (14th January 2019).

10. Pietruszyńska, K. Prawo pracy - informator dla kobiet w ciąży. Warszawa: Państwowa Inspekcja Pracy, 2018. https://www.pip.gov.pl/pl/ f/v/190121/PrawoPracy-InforKobCiaza-wyd3-Intern.pdf(14th January 2019).

11. Bundesministeriums der Justiz und für Verbraucherschutz. Gesetz zum Schutz von Müttern bei der Arbeit, in der Ausbildung und im Studium (Mutterschutzgesetz - MuSchG). https:// www.gesetze-im-internet.de/muschg_2018/BJNR122810017. html\#BJNR122810017BJNG000200000 (14th January 2019).

12. Toth $B$, Strowitzki T, Wallwiener $M$, et al. Heidelberger Schwangerschafts\& Elternzeitprogramm (HeiSEP). https://www.klinikum.uni-heidelberg. de/Heidelberger-Schwangerschafts-Elternzeitprogramm-HeiSEP.129792.0.html (14th January 2019).

13. Donaldson J. Infection Control Today - Operating Room - Hazardous Materials Emergencies in Surgery. http://beta.infectioncontroltoday. com/infections/infection-control-today-operating-room-hazardous-materials-emergencies-surgery (14th January 2019).

14. Heinonen S, Saarikoski S. Reproductive risk factors, pregnancy characteristics and obstetric outcome in female doctors. BJOG. 2002; 109(3): 261-264, indexed in Pubmed: 11950180.
15. Lynch L, Spivak ES. The pregnant healthcare worker: fact and fiction. Curr Opin Infect Dis. 2015; 28(4): 362-368, doi: 10.1097/QCO.0000000000000180, indexed in Pubmed: 26098508.

16. Nienhaus A, Kesavachandran C, Wendeler D, et al. Infectious diseases in healthcare workers - an analysis of the standardised data set of a German compensation board. J Occup Med Toxicol. 2012; 7(1): 8, doi: 10.1186/1745-6673-7-8, indexed in Pubmed: 22553942.

17. Główny Inspektorat Sanitarny. Czynniki biologiczne występujące w miejscu pracy. https://gis.gov.pl/zdrowie/szkodliwe-czynniki-biologiczne-wystepujace-w-miejscu-prac/ (14th January 2019).

18. Dutkiewicz J, Cisak E, Sroka J, et al. Biological agents as occupational hazards - selected issues. Ann Agric Environ Med. 2011; 18(2): 286-293, indexed in Pubmed: 22216801.

19. Wicker S, Rabenau HF, Haberl AE, et al. Blood-borne infections and the pregnant health care worker. Risks and preventive measures. Chirurg. 2002; 83(2): 136-142, doi: doi: 10.1007/s00104-011-2166-9.

20. Győrffy Z, Dweik D, Girasek E. Reproductive health and burn-out among female physicians: nationwide, representative study from Hungary. BMC Womens Health. 2014; 14: 121, doi: 10.1186/1472-6874-14-121, indexed in Pubmed: 25273522.

21. Sheiner E, Sheiner EK, Potashnik G, et al. The relationship between occupational psychological stress and female fertility. Occup Med (Lond). 2003; 53(4): 265-269, doi: 10.1093/occmed/kqg069, indexed in Pubmed: 12815124.

22. Waters TR, Dick RB. Evidence of health risks associated with prolonged standing at work and intervention effectiveness. Rehabil Nurs. 2015; 40(3): 148-165, doi: 10.1002/rnj.166, indexed in Pubmed: 25041875.

23. Kramer MS, McDonald SW. Aerobic exercise for women during pregnancy. Cochrane Database Syst Rev. 2006(3): CD000180, doi: 10.1002/14651858.CD000180.pub2, indexed in Pubmed: 16855953.

24. Gaudineau A. [Prevalence, risk factors, maternal and fetal morbidity and mortality of intrauterine growth restriction and small-for-gestational age]. J Gynecol Obstet Biol Reprod (Paris). 2013; 42(8): 895-910, doi: 10.1016/j.jgyn.2013.09.013, indexed in Pubmed: 24216305.

25. Beck $S$, Wojdyla $D$, Say $L$, et al. The worldwide incidence of preterm birth: a systematic review of maternal mortality and morbidity. Bull World Health Organ. 2010; 88(1): 31-38, doi: 10.2471/BLT.08.062554, indexed in Pubmed: 20428351.

26. Chmaj-Wierzchowska K, Pięta B, Buks J, et al. Determinants of favourable neonatal outcome after premature rupture of membranes (PROM) before 24 weeks of pregnancy--review of the literature and a case report. Ann Agric Environ Med. 2012; 19(3): 577-580, indexed in Pubmed: 23020060.

27. Downes J, Rauk PN, Vanheest AE. Occupational hazards for pregnant or lactating women in the orthopaedic operating room. J Am Acad Orthop Surg. 2014; 22(5): 326-332, doi: 10.5435/JAAOS-22-05-326, indexed in Pubmed: 24788448.

28. Behbehani S, Tulandi T. Obstetrical Complications in Pregnant Medical and Surgical Residents. Journal of Obstetrics and Gynaecology Canada. 2015; 37(1): 25-31, doi: 10.1016/s1701-2163(15)30359-5.

29. Zhang J, Cai WW, Lee D. Occupational hazards and pregnancy outcomes. American Journal of Industrial Medicine. 1992; 21(3): 397-408, doi: 10.1002/ajim.4700210312.

30. Zadeh HG, Briggs TW. lonising radiation: are orthopaedic surgeons' offspring at risk? Ann R Coll Surg Engl. 1997; 79(3): 214-220.

31. Bolyard E, Tablan O, Williams W, et al. Guideline for infection control in health care personnel, 1998. American Journal of Infection Control. 1998; 26(3): 289-327, doi: 10.1016/s0196-6553(98)80015-1.

32. Dzau VJ, Kirch DG, Nasca TJ. To Care Is Human - Collectively Confronting the Clinician-Burnout Crisis. N Engl J Med. 2018; 378(4): 312-314, doi: 10.1056/NEJMp1715127, indexed in Pubmed: 29365296.

33. Roberts DL, Shanafelt TD, Dyrbye LN, et al. A national comparison of burnout and work-life balance among internal medicine hospitalists and outpatient general internists. J Hosp Med. 2014; 9(3): 176-181, doi: 10.1002/jhm.2146, indexed in Pubmed: 24435981. 